\section{COLIC IN AN INFANT DUE TO ADENOID HYPERTROPHY}

\section{C. WALLIN, M.D.}

\author{
LEWISTOWN, MONT.
}

On reading Dr. Freeman's article entitled "Adenoid Hypertrophy During the First Year of Life and Its Treatment," I am constrained to report the following case. I well recall Dr. Morse's paper of two years ago, but neither in it nor in any other discussions of conditions induced by the hypertrophied adenoid have I seen attention called to the symptoms herein reported.

The case is that of a child about six weeks old, perfectly healthy and nursed by its mother, who was also in good condition. I was called one evening to see the infant-which I had delivered-on account of an attack of "wind colic." An enema brought relief, but the condition recurred the next day. The child was plainly a mouth breather, and according to the mother had difficulty in nursing as well as frequent attacks of colic. Examination with the little finger revealed a nasopharynx pretty well filled with adenoid growth. The child was placed on a small table, the father steadied the head while with an ordinary tongue depressor, the lower jaw was depressed and the smallest Beckman curette inserted. It was but the work of a moment to clean out the growth, and from that time on the child has had no colic.

In this instance the colic was due simply to the fact that, in its efforts to nurse, the child swallowed quantities of air. This is shown by the utter absence of any other symptoms of digestive disturbance and by the result of the operation.

As to the prevalence of hypertrophied adenoids in infants, I am convinced that it is far greater than usually recognized. An infant with normal air passages will keep its mouth closed, and "snuffles" and "catarrh" are more often due to adenoid hypertrophy than to syphilis or to any other condition. Neither "snuffles" nor "catarrh" invariably accompany even a decided overgrowth of the adenoid.

I am further convinced that it is rarely necessary to administer an anesthetic for the removal of adenoids in a child under a year old; indeed, I believe such a course is rarely justifiable.

Reconstruction of Bile Ducts.-Dr. Alfred H. Movius, Jamestown, N. D., writes that Dr. Arthur G. Sullivan's article on this subject in The Journal, Sept. 4, 1909, p. 774, suggests to him that a recent case, in which he did a partial reconstruetion of the common duct, might be worth reporting. It is as follows: Patient: A Norwegian woman, aged 82, who had suffered with gall-stone colic for twenty years, came under observation in June, 1908. The skin over the entire body was decidedly jaundiced; more or less jaundice had been present for the past three months. The stools were clay-colored; the urine loaded with bile. A diagnosis of cholelithiasis with stone in common duct was made. Operation: The usual incision was made in the right hypochondrium. The gall-bladder was found to be atrophied and full of stones. After loosening the extensive adhesions, the gall-bladder was removed. The common duct was next opened and the stone removed. The lumen of the common duct, below the location of the stone, was very much contracted. Fearing occlusion of this portion of the duct and consequent poor drainage, Dr. Movius inserted a piece of rubber tubing $3 / 16$ inch in diameter. The tube extended from $1 / 4$ inch above the incision in the common duct to $1 / 3$ inch into the duodenum. The duct was then sutured with No. 1 chromicized catgut, one stitch passing through the rubber tube to hold it in place. The abdominal wound was closed in the usual way. Postoperative History: Drainage was left in for four days, after which time it was removed and wound allowed to heal. Healing was complete in eight days. The bowels showed active bile drainage within the first thirty-six hours and the urine contained very little bile. The rubber tube passed on the fourteenth day following operation. The patient left the hospital at the end of the fourth week.

\section{Therapeutics}

\section{CARE OF THE MOUTH}

Dr. S. Blair Luckie, of Chester, Pa. (Dietetic and Hygienic Gazette, June, 1909), says so many pertinent things in regard to the proper care of the mouth preventing disease that it is well to review his article. The mouth seems to be splendidly arranged for the propagation and even protection of bacteria. There are cavities, caverns, and crypts, not easily cleansed, which are moist and warm, and more or less food is deposited near or in these spaces, which forms suitable pabulum for the growth of bacteria. A disturbance of the general health may change the mucous and salivary secretions and may impair the health of the mucous membrane of the mouth. Digestive disturbances not only coat the tongue, but interfere with the health of the rest of the mouth. Decayed teeth or painful roots of the teeth cause the patient to avoid that side of the mouth in masticating. One or all of these conditions may be present and allow the growth and propagation of pathologic bacteria in the mouth. In fact, there is hardly a general disturbance that does not interfere with the normal health of the mouth, which means good teeth; clean, pink mucous membranes; normal saliva; good digestion; and sweet breath. When one remembers how generally the breath of an individual is not sweet; how generally the tongue is not clean; how generally there is some tooth or teeth abnormality in a patient; and how incompletely most patients cleanse their mouths and teeth, we should not be astonished to learn that not only are harmless bacteria more or less constantly present in the mouth, but that pathologic bacteria occurring in the mouth are the cause of many serious diseases.

Unfortunately, an individual does not always realize that his mouth is dirty. Before he notices it there has to be considerable inflammation, considerable disturbance of secretions, and a bad taste in his mouth. Luckie quotes Miller as stating that one unclean mouth harbors $1,140,000,000$ bacteria that may be cultivated, many of which are pathogenic. It has been shown that some of these pathogenic bacteria may cause not only intestinal indigestion and putrefaction, but may even be a source of pernicious anemia. A healthy gastric juice kills most of these germs that are swallowed, but anything that interferes with the normal amount of hydrochloric acid in the stomach may allow these germs to be carried into the intestines unharmed, where they can continue to grow. Besides the septic bacteria, the pneumococcus, the bacillus of diphtheria, and the bacillus of tuberculosis are sometimes found in the mouth.

The frequency of alveolitis and gingivitis after forty, even in otherwise normal individuals, shows neglect in the care of the mouth.

These bacteria, harmless or harmful, which are present in the mouth, may be inhaled, may be swallowed, may be chewed into the food, may be sprayed during sneezing or coughing, and may be offered gratuitously to friends who are kissed.

The object of this article is to cause the physician, whenever he is consulted by any patient, to examine the mouth carefully, and to give careful advice for daily continued cleanliness; the character of the solutions he deems advisable to order, depending on the condition in which he finds the mouth. He should also urge the patient to consult his dentist immediately if there is any cleaning or filling of the teeth needed. He should also instruct mothers in the care of their children's mouths. 